\title{
Jogos matemáticos e reciclagem: unificação com impactos
}

\author{
Alana Cavalcante Felippe ${ }^{1}$ \\ DMA, Viçosa, MG \\ Shirley da Silva Macedo² \\ IMTEC, Catalão, GO
}

\begin{abstract}
Resumo A falta de diálogo entre o ensino e a aprendizagem da matemática tem gerado a desmotivação dos alunos na realização de atividades, ampliando a dificuldade de estabelecer relações entre a matemática e o cotidiano. A realidade, em muitas salas de aula, ainda é a de um ensino de matemática fragmentado e fora do contexto do dia a dia, por isso, a importância de utilizar materiais recicláveis para a construção de materiais didáticos, dando ênfase à educação ambiental, tem sido uma alternativa que potencializa o ensino dessa matéria na educação básica. A fim de contribuir no processo de ensino e aprendizagem de matemática em uma escola pública de João Monlevade/MG, foram desenvolvidos, em dois projetos de extensão, vários jogos matemáticos, construídos a partir de materiais recicláveis.
\end{abstract}

Palavras-chave. Matemática, reciclagem, ensino-aprendizagem, educação ambiental.

\section{Introdução}

No decorrer dos últimos anos, vemos que o ensino de matemática está passando por um momento reflexivo, acerca de didáticas e metodologias que proporcionem um ensino com aprendizagem significativa, traduzidos por baixos resultados nos exames mundiais. Segundo dados do Programa Internacional de Avaliação de Estudantes (PISA), no ranking de matemática, o Brasil ocupa a $72^{\mathrm{a}}$ posição entre os 79 países participantes da última edição, ocorrida em 2018.

As pesquisas apontam, entre outras causas, a falta de motivação dos alunos para aprendizagem escolar, o que se deve, entre outros fatores, ao uso de metodologias de ensino tradicionais, baseadas na memorização de regras, fórmulas e à apresentação de conteúdos desvinculados da realidade dos alunos. Conforme os Parâmetros Curriculares Nacionais (PCN's) [3], a atividade matemática escolar não é "olhar para coisas prontas e definitivas", mas a construção e a apropriação de um conhecimento pelo aluno, que se servirá dele para compreender e transformar sua realidade.

De acordo com Lachini [6], para atingir a melhoria da aprendizagem em matemática, é preciso ir além da simples transmissão de regras, fórmulas e teorias, que nem sempre possibilitam o entendimento e a reflexão e que, na verdade, só reproduzem mecanicamente um algoritmo ou um formato pré-estabelecido.

É necessário desenvolver no aluno a curiosidade, a criatividade, a autoconfiança e a percepção da matemática como um desafio que ele pode vencer. Sendo assim, devemos propor atividades que os levem a entender as questões que envolvem a matéria e sua utilidade prática, que permitam que ele experimente e tire suas próprias conclusões. A educação por meio de atividades lúdicas tem-se tornado, nas últimas décadas, uma alternativa metodológica bastante pesquisada, utilizada e abordada em vários aspectos, pois potencializam as capacidades que estão temporariamente

\footnotetext{
1alana@ufv.br

2 shirleymacedo@ufg.br
} 
inativas nos alunos, no que refere ao aprendizado da matemática, isso porque mudam a rotina da classe, despertando o interesse dos envolvidos. Deve-se enfatizar que a atividade lúdica não deve fazer parte, por completo, de todo o processo de ensino e aprendizagem, ela será uma ferramenta utilizada de forma a proporcionar uma aproximação dos alunos com a matemática, colaborando na relação professor-aluno.

Além disso, atividades lúdicas como um instrumento educativo, em conjunto com materiais concretos, estão relacionadas ao desenvolvimento cognitivo do aluno, uma vez que despertam o senso crítico e investigador, promovendo a intervenção do indivíduo nos fenômenos sociais e culturais, ajudando a construir conexões necessárias.

Paralelamente à questão da dificuldade dos alunos em matemática, um problema de outra área do conhecimento, mas que está sendo cada vez mais discutido, é a reciclagem. Nos últimos anos, as questões ambientais estiveram em evidência e as pessoas começaram a fazer uma releitura no que refere às ações preservativas ao meio ambiente. Diante desse contexto, criando uma consciência ecológica nos alunos, aumentamos a chance de que se tornem adultos responsáveis pela preservação do planeta. Fazendo a conexão entre as duas áreas do conhecimento, a matemática pode ensinar, por exemplo, porque reciclar uma caixa de leite, ou uma latinha de alumínio, é tão importante para o meio ambiente e para a economia do Brasil. Nesse compasso, a inclusão de jogos matemáticos confeccionados com materiais recicláveis tem um valor educacional intrínseco, pois promove o desenvolvimento das capacidades intelectuais, cognitivas e sociais dos alunos, estimula a curiosidade, a autoconfiança e o conhecimento lógico matemático, auxiliando na criação de estratégias para a solução de possíveis problemas, com objetos conhecidos e presentes no cotidiano dos alunos. Além disso, promove a sensibilidade para as questões ambientais.

Nos dias atuais, os jogos matemáticos vêm se destacando como um recurso didático utilizado para a melhoria da qualidade do processo de ensino aprendizagem. Sendo assim, este trabalho visou vincular conteúdos matemáticos a um problema de outra área do conhecimento, a reciclagem, intensificando sua importância no meio ambiente, a partir de conteúdos matemáticos do $6^{\underline{0}}$ e do $8^{0}$ ano do Ensino Fundamental.

\section{Referencial Teórico}

Um registro na contextualização educacional foi a elaboração da Lei n⿳0 9.394, de 20 de dezembro de 1996, conhecida como a Lei de Diretrizes e Bases da Educação 9394/96 (LDB), a qual tem como condição necessária que a escola ofereça uma aprendizagem significativa, servindo aos interesses da sociedade, e garanta a todos os estudantes uma boa qualidade no ensino. Em outras palavras, é necessário que os conteúdos escolares sejam apresentados de modo que proporcionem a compreensão do mundo nos quais os educandos estão inseridos. A matemática tem uma participação importante nesse processo de contextualização, pois pode contribuir para as relações interpessoais e na qualidade do processo de ensino aprendizagem.

Para Tufano [7], contextualizar é um ato de colocar no contexto, ou seja, colocar alguém a par de algo, alguma coisa, uma ação premeditada para situar um indivíduo em um lugar no tempo e no espaço desejado; é encadear ideias em um escrito, é constituir o texto no seu todo, é argumentar. Tufano diz também que contextualizar é função inicial e talvez uma das principais atribuições do professor em sua sala de aula, transformando essa caminhada, antes árdua, em um processo feliz, prazeroso.

Fonseca [4] ressalta que contextualizar é ir além das técnicas e da compreensão, é compreender os conteúdos matemáticos dentro dos contextos históricos, sociais e culturais que foram construídos.

Nas instituições de ensino fundamental e médio, a realidade do ensino de matemática ainda passa pelo crivo de uma matemática distante do contexto do cotidiano, porque se prioriza um ensino em que predomina a mecanização e a memorização, o que as fazem classificá-las como instituições 
atadas a planos rígidos, principalmente referente ao ensino da matemática. Em busca de soluções que minimizem as diversas dificuldades dos alunos no ensino dessa disciplina, novas metodologias vêm sendo estudadas por educadores e pesquisadores. Atividades lúdicas têm sido utilizadas nas últimas décadas como uma alternativa pedagógica bastante procurada, uma vez que a educação por meio de atividades lúdicas tem exercido uma influência nas escolas de ensino fundamental e médio. Ludicidade é uma maneira de desenvolver a criatividade, acoplada a uma participação ativa dos envolvidos.

O lúdico influencia muito no desenvolvimento da criança, uma vez que sua curiosidade é estimulada. Além disso, proporciona o desenvolvimento da linguagem, do pensamento e da concentração, fazendo com que a criança possa adquirir iniciativa e autoconfiança, conforme Vygotsky [9].

Nesse compasso, é importante reportarmo-nos a Freire [5], o qual afirma que, nas condições da aprendizagem, os educandos vão se transformando em reais sujeitos da construção e, também, na reconstrução do saber.

Nessa perspectiva, atualmente, a inclusão de jogos nas atividades de conteúdo matemático estão sendo agentes fomentadores na aprendizagem matemática. Borin [2] afirma que os jogos abrem as possibilidades para a diminuição de bloqueios de aprendizado por parte de muitos alunos. E Agranionih e Smaniotto [1] definem o jogo matemático como uma atividade lúdica e educativa, que tem a capacidade de, a partir de objetivos claros, fornecer estratégias para a resolução de problemas.

No que tange à reciclagem, no fim dos anos 1980, as questões ambientais estiveram em evidência, visto que as pessoas começaram a intensificar suas observações sobre o nosso planeta, as quais foram pautadas na má conservação do meio ambiente, incluindo as enchentes recorrentes, a poluição, a má qualidade do ar que respiramos, ou seja, ações prejudiciais do homem para com o meio ambiente. Nesse contexto, houve a necessidade de inserir uma educação voltada para a conservação do meio ambiente, conhecida como educação ambiental. Assim, iniciaram os processos de reciclagem, que têm sido objeto de estudo nos ambientes escolares.

Para Valle [8], a reciclagem permite reutilizar um produto de uma maneira diferenciada. Ao utilizar um produto, um ciclo é feito, e na reutilização, é refeito. Percebe-se, diante desse contexto, que, na medida em que existem as dificuldades no ensino e na aprendizagem de conteúdos matemáticos vistos em salas de aula, também existe a necessidade de buscar e desenvolver alternativas diferenciadas que fomentem a preservação do meio ambiente de forma consciente, constante e permanente.

Sendo assim, a confecção de jogos matemáticos com materiais recicláveis tem contribuído para uma aprendizagem matemática eficaz, já que auxilia tanto no trabalho do professor, que pode tornar o seu planejamento mais dinâmico e atrativo, quanto no entendimento dos alunos, que têm a oportunidade de construir seus conhecimentos de forma prazerosa, dinâmica e inclusiva. Jogos matemáticos feitos com reciclagem aproximam os alunos das questões atuais que fazem parte do cotidiano do educando e auxiliam na aprendizagem, pois partem de informações já conhecidas pelo aluno, proporcionando uma melhoria da qualidade do processo de ensino aprendizagem.

\section{Desenvolvimento}

As atividades desenvolvidas e aplicadas foram realizadas em grupo, o que contribuiu para incentivar trabalho em conjunto, desenvolvimento de estratégias, apoio e compreensão de cada um em equipe. Ademais, todos os materiais utilizados eram recicláveis, levando à conscientização ambiental. Além da coleta seletiva, os conceitos matemáticos trabalhados foram: Operações Básicas, Proporção, Grandezas diretamente proporcionais, Regra de três, Porcentagem, Equações, Construção de gráficos e tabelas, Circunferência, Ângulos, Poliedros, Retas, Polígonos, Identificação das figuras geométricas. Foram realizadas as seguintes atividades: Baralho Matemático, Bingo, Corrida 
Matemática, Divisão em Linha, Dominópera, Jogo da Memória, Jogos On-line, Monte a Operação, Operuno, Dama Matemática, MMC Geométrico, Poliedros, Boliche, gincana geométrica.

Descreveremos aqui algumas das atividades realizadas:

\section{Atividade: Corrida Matemática}

O objetivo dessa atividade foi trabalhar de forma lúdica as operações básicas de soma e subtração, uma vez que percebemos que os alunos do $6^{\underline{0}}$ ano apresentavam bastante dificuldade em realizar contas simples. Ela também foi explorada posteriormente utilizando as operações de multiplicação e divisão.

Elaboração: Para a construção do Tabuleiro, foram utilizadas caixas de ovos de 30 unidades, pintadas de preto. Nos topos das marcações, onde ficam os ovos, foram colados papéis coloridos a fim de demarcar a trilha de cada jogador. Foi criada também uma roleta, enumerada de 1 a 10, onde foi utilizado um CD como base. A seta da roleta foi confeccionada utilizando caixa de leite; tampinhas de garrafa, parafusos e porcas fazem o mecanismo de girar a seta. Os peões do tabuleiro foram feitos de tampinhas de garrafa furadas com um palito de dente, contendo a imagem de um desenho infantil que representa cada jogador.

Regras: Para essa atividade, o jogo terá cinco participantes, os quais devem girar a roleta duas vezes na ida, somando os dois números obtidos. Se o aluno acertar, avança uma casa e caso contrário, mantém-se na mesma posição em que estava. Ao alcançar o fim do tabuleiro, o participante deverá novamente girar a roleta duas vezes e voltar no sentido contrário. No entanto, a operação que ele deverá realizar é a subtração dos números obtidos ao rodar a roleta (sempre subtraindo o maior número do menor, para que não haja números negativos como resultado). $\mathrm{O}$ aluno que chegar ao início do tabuleiro é o vencedor.

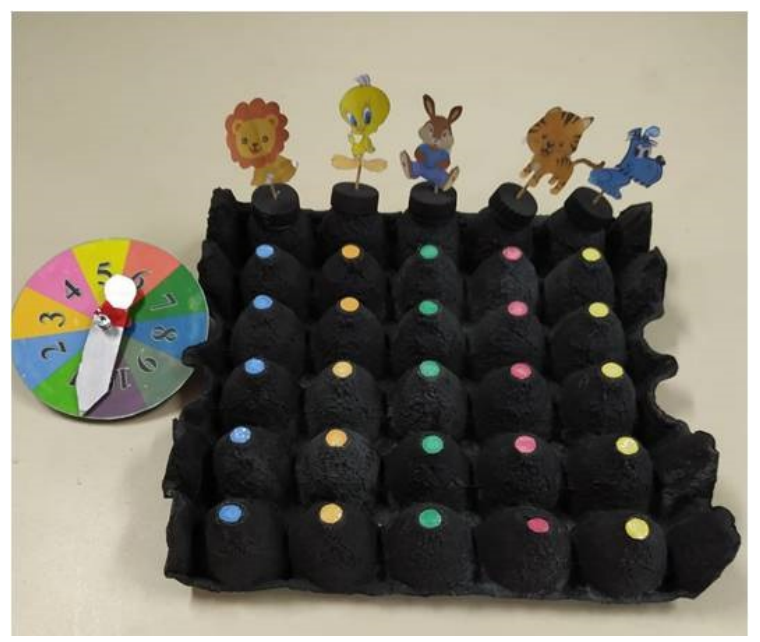

Figura 1: Tabuleiro da Corrida matemática.

\section{Atividade: Boliche de Frações}

O objetivo dessa atividade foi trabalhar o conceito de fração aliado à competição que o próprio boliche gera. Para isso, foram coladas frações em garrafas PET's e o maior resultado da soma 
das garrafas que eram derrubadas com o lançamento da bola, determinava a equipe vencedora da rodada. No final da atividade os alunos perceberam que não era necessário que todas as garrafas caíssem no chão, como é a regra do boliche, mas que eles deveriam derrubar as garrafas que tinham as frações cuja soma resultasse no maior número para vencer a rodada.

Elaboração: Foram necessários para a elaboração do boliche: garrafas PET's, papel para a confecç̧ão da bola para arremesso nos boliches, frações específicas para o aprendizado do conteúdo.

Regras: A turma deve ser dividida em grupos de 5 a 6 pessoas. Haverá 6 etapas do boliche, em que cada aluno de cada grupo será responsável por fazer a jogada, e conforme o número de garrafas que caírem no chão, a soma das frações que estão afixadas nas garrafas será pontuada para a equipe. Assim, após todos os alunos realizarem os arremessos, deverão ser somadas todas as pontuações do respectivo grupo. Após as 6 rodadas, o grupo que tiver a maior pontuação vencerá a competição. Durante as etapas, penalidades como, por exemplo, conversa paralela entre os grupos, e erro na operação, serão aplicadas, a fim de que se trabalhe a subtração das frações. Ademais, durante o jogo de boliche, o método matemático aplicado está na identificação, propriedades e nas operações entre frações.

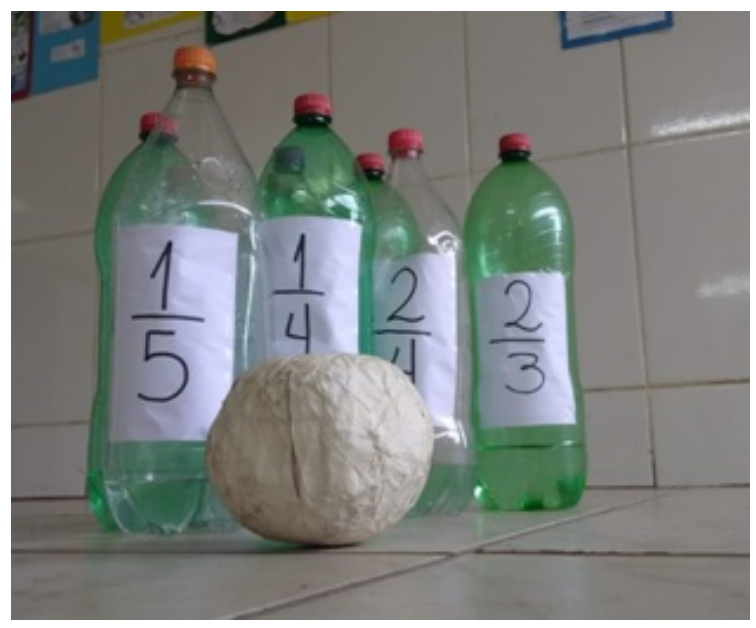

Figura 2: Boliche das Frações.

\section{Atividade: Jogo da memória}

Nessa atividade também trabalhamos com as operações básicas, visto que os alunos precisavam dominar todas elas para entender os outros conceitos matemáticos vistos durante o ano. Além disso, como essa atividade foi aplicada na semana da Páscoa, foi desenvolvido um porta treco, que os alunos puderam levar de lembrança para casa.

Elaboração: Para a elaboração da atividade foi necessária a confecção de 32 cartas em formato de ovos feitos de papel cartão, com $4 \mathrm{~cm}$ de diâmetro. A metade dessas cartas continha operações matemáticas e a outra metade o resultado dos cálculos das operações.

Regras: As regras da atividade são semelhantes às regras de um jogo da memória comum, sendo assim, a turma é dividida em duplas. Todas as cartas devem ser espalhadas sobre a mesa e ter seus escritos virados para baixo. O primeiro jogador vira uma carta, resolve a operação e, em seguida, 
procura o resultado correto em outra carta da mesa. Se encontrar a carta igual, que fará par com a primeira, poderá virar outra carta e procurar seu par novamente. Caso contrário, se a segunda carta não fizer par com a primeira, deverá voltar as duas cartas para a posição inicial e passar a vez para o outro jogador. Ao final de todas as rodadas, os participantes devem somar as cartas individuais conquistadas. O vencedor é o aluno que obtiver a maior soma das cartas obtidas.

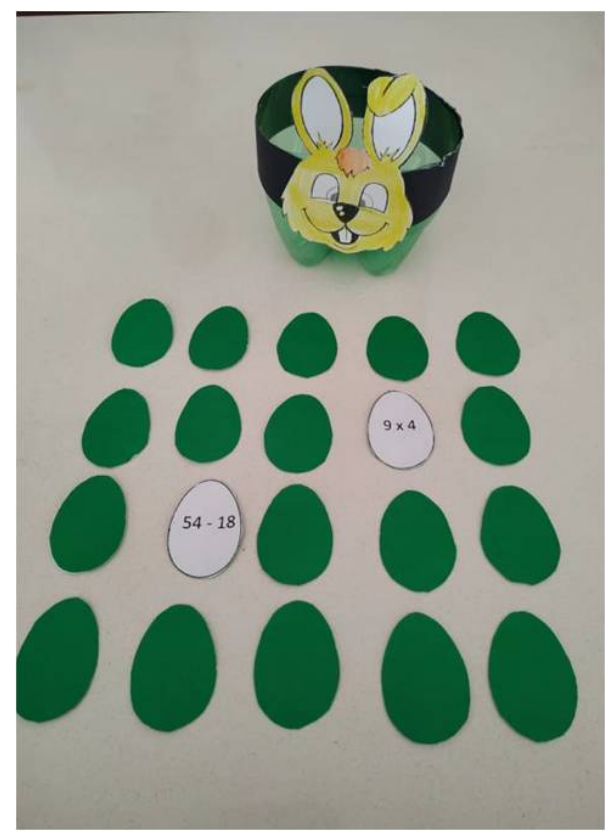

Figura 3: Jogo da memória.

\section{Conclusões}

Através dos projetos extensionistas, toda equipe pôde vivenciar a realidade do ensino em uma escola pública da cidade de João Monlevade, em Minas Gerais. Percebemos que o número de alunos com dificuldades em matemática é significativamente grande, eles apresentam fragilidades em raciocínios lógicos que, a critério, já deveriam ter sido superados nas séries anteriores àquela em que estão inseridos. Dessa maneira, as aulas expositivas dos conteúdos matemáticos explicados de formas tradicionais não são suficientes para sua fixação absoluta. De acordo com os diagnósticos a respeito da metodologia de ensino utilizada nas atividades apresentadas, percebemos também um avanço considerável da maior parte dos alunos, uma vez que esta abordagem facilitou a compreensão dos temas abordados.

Um ponto importante a se destacar, ainda, é que conseguimos mostrar aos estudantes a importância da reciclagem através de objetos comuns do cotidiano, que podem ser transformados em jogos e atividades matemáticas muito interessantes, por exemplo, garrafas PET's, caixas de leite, palitos, tampinhas, entre outros.

Sob uma visão amplificada, percebemos que os projetos contribuíram de modo positivo para a melhoria do ensino e da aprendizagem da Matemática nessa escola. Os alunos participantes das atividades pediam para os professores que as aulas de matemática fossem sempre com a participação 
dos monitores dos projetos de extensão, o que demonstra a influência positiva e motivadora que esses projetos têm proporcionado a todos os envolvidos, já que funcionam com a cooperação ativa dos alunos orientandos, professores coordenadores dos projetos, diretoria, coordenação e professores da escola. Essas ações extensionistas têm deixado seus registros positivos, e estamos trabalhando para que um número maior de alunos e escolas estejam conosco agregados.

\section{Agradecimentos (opcional)}

Agradecemos à Universidade Federal de Goiás pela credibilidade a nós fornecida na execução dessas ações extensionistas. Agradecemos aos alunos e alunas orientandos que se uniram nesse propósito da unificação de jogos e educação ambiental. Estendemos nossas considerações à diretoria, aos professores e aos coordenadores das séries da escola onde essas ações foram desenvolvidas pelo empenho e pela colaboração no objetivo único, que é trazer a melhoria diária no processo de ensino aprendizagem da matemática em nosso país.

\section{Referências}

[1] Agranionih, N. T., Smaniotto, M. Jogos e aprendizagem matemática: uma interação possível, Erechim, Edifapes, 2002.

[2] Borin, J. Jogos e Resolução de Problemas: Uma estratégia para as aulas de matemática. 2a edição, IME-SP, São Paulo, 1996.

[3] Brasil, Secretaria de Educação Fundamental. Parâmetros Curriculares Nacionais: Matemática. Brasília: $M E C / S E F, 1998$. Disponível em: http://midia.cpt.com.br/pdfs/cpt/pcn/volume-03matematica.pdf. Acesso em 08 de março 2020.

[4] Fonseca, M. C. F. R. Por que ensinar Matemática. Presença Pedagógica, Belo Horizonte, volume 1, número 6, 1995.

[5] Freire, P. Pedagogia da autonomia, 25 edição, Paz e Terra, São Paulo, 1996.

[6] Lachini, J. Como está pensado o trabalho com Matemática .In: Tomelin, Honório e Filho, João Gomes (orgs.). Educação: gestão do Conhecimento e da aprendizagem, Una Editoria, Belo Horizonte, 2001.

[7] Tufano, W. Contextualização. In: Fazenda, I. C. Dicionário em Construção: Interdisciplinaridade, Cortez, São Paulo, 2001.

[8] Valle, C. E. Qualidade ambiental: como ser competitivo protegendo o meio ambiente, Pioneira, São Paulo, 1995.

[9] Vygotsky, L. S. Linguagem, desenvolvimento e aprendizagem, Edusp, São Paulo, 1988. 